\title{
Left atrial myxoma with extensive calcification
}

\author{
J STEWART, NR SAUNDERS
}

From the Cardiothoracic Unit, Killingbeck Hospital, Leeds

Primary cardiac tumours are rare and may be difficult to diagnose. Fifty per cent are myxomas and $75 \%$ of these arise in the left atrium. Patchy calcification within atrial myxomas has been noted infrequently but extensive calcification is rare. This paper reports such a case in which the mass was found during investigations for severe mitral regurgitation.

\section{Case report}

The patient was a 61-year-old male engineer whose history started in May 1977 with symptoms of mild dyspnoea on exercise and occasional palpitations. He had not had rheumatic fever and there was no family history of cardiac disease. He smoked 15 cigarettes per day. Examination at that time had revealed a malar flush, atrial fibrillation at 90 beats per minute, a blood pressure of $160 / 100 \mathrm{mmHg}$, a forceful apex beat, and an apical systolic murmur. A diagnosis of mild mitral regurgitation was made and digoxin $0.25 \mathrm{mg}$ daily started to control his fibrillation. He stopped smoking and remained symptom-free until January 1980 . His condition then deteriorated markedly with increasing dyspnoea, orthopnoea, paroxysmal nocturnal dyspnoea, and ankle oedema. A chest radiograph showed a marked increase in heart size and the ECG showed atrial fibrillation with right bundle branch block. His cardiac failure was controlled with digoxin, $0.25 \mathrm{mg}$ daily, frusemide $80 \mathrm{mg}$ daily, and slow $\mathrm{K} 600 \mathrm{mg}$ tds.

In April 1980 he was referred to the Cardiothoracic Unit at Killingbeck Hospital, Leeds for possible mitral valve replacement. Examination revealed dyspnoea on mild exertion, controlled atrial fibrillation, a blood pressure of $110 / 70 \mathrm{mmHg}$, and a normal jugular venous pressure. His apex beat was in the sixth intercostal space in the anterior axillary line and a systolic thrill was palpable. A pansystolic murmur was audible over the praecordium, maximal at the apex and radiating to the left axilla. Bilateral basal crepitations were present. Clinically, he appeared to have moderate to severe mitral regurgitation.

Investigations showed a haemoglobin of $14.4 \mathrm{~g} / \mathrm{dl}$ with a normal white cell count, differential, and sedimentation rate. Chest radiography revealed an enlarged heart with an oval calcified mass lying in the region of the left atrium on the lateral view (fig 1). M-mode echocardiography indicated severe mitral regurgitation with good left ventricular function. The left atrium was moderately

Address for reprint requests: Mr NR Saunders, Senior Registrar, Cardiothoracic Unit, Leeds General Infirmary, Leeds LSI 3EX.

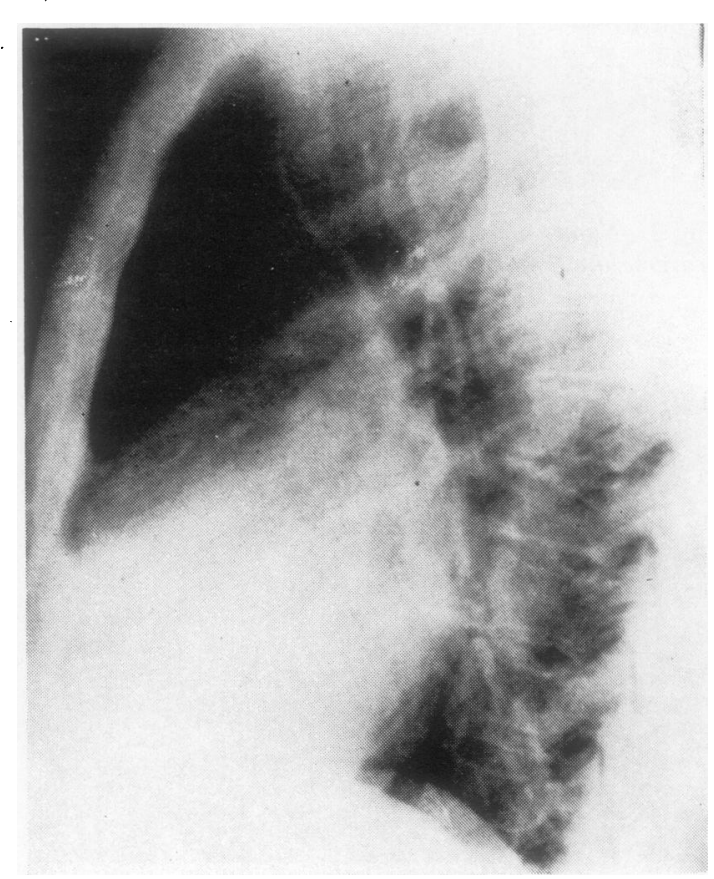

Fig 1 Left lateral chest radiograph showing calcified left atrial mass.

enlarged and contained a large calcified space occupying lesion which was attached to the posterior wall and moved anteriorly in systole. Left ventricular angiography confirmed good function of the left ventricle which was mildy enlarged. The aortic valve was normal. The mitral valve showed some prolapse with moderate regurgitation into an enlarged left atrium. Within the atrium was an $\mathrm{N}$ oval filling defect, which showed widespread craggy $ᄋ$ calcification and was attached posteriorly. This did not $\mathrm{N}$ interfere with mitral valve opening. Coronary angiography showed patchy atheromatous disease but no lesions of surgical significance. The mass was thought to be either a calcified left atrial tumour or a calcified ball thrombus, in a patient with mitral regurgitation.

Operation was performed using cardiopulmonary bypass and hypothermic cardioplegic arrest on the 20 May 1980. The heart was moderately enlarged and the calcified mass was easily palpable in the left atrium. A left atriotomy, extending into the right atrium inferiorly was performed. This revealed a stone-hard calcified mass 
$5.5 \times 3.5 \times 3 \mathrm{~cm}$, attached to the posterolateral aspect of the septum by a short pedicle, together with rupture of the central chordae to the posterior leaflet of the mitral valve. This allowed the posterior leaflet to prolapse into the left atrial cavity. The remaining chordae were thin and elongated (fig 2). A small secondum type atrial septal defect $\left(1 \times 1 \frac{1}{2} \mathrm{~cm}\right)$ was also present.

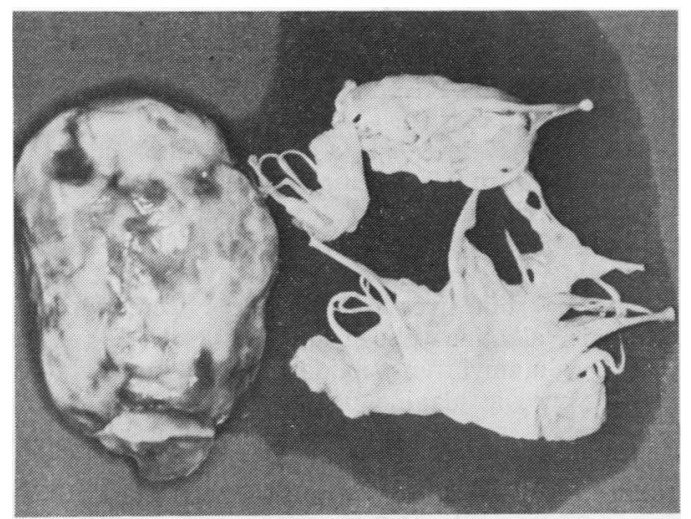

Fig 2 Calcified left atrial myxoma and excised mitral valve leaflets.

The left atrial tumour was excised together with a small disc of septum and the septum closed with a prolene suture which also closed the septal defect. The mitral valve was excised and replaced with a porcine xenograft (size $31 \mathrm{~mm}$ ). The postoperative course was uneventful and the patient was discharged from hospital on the 11 June 1980. When last reviewed on 10 March 1981, he was asymptomatic.

Histological examination of the left atrial mass showed extensive calcification with areas of old and recent haemorrhage. The appearances were those of a degenerate calcified atrial myxoma. Both leaflets of the mitral valve showed mucoid degenerative changes.

\section{Discussion}

Mucoid degeneration of the mitral valve is found in approximately one per cent of necropsies on patients over 50 years of age and is more common in males. It is often associated with mitral regurgitation which is usually well tolerated in this condition. The most common complication of mucoid degeneration of the mitral valve is chordal rupture and this most frequently affects the posterior leaflet chordae. ${ }^{12}$ This event may cause the death of the patient or a rapid clinical deterioration as seen in this case.

A calcified myxoma visible on a plain chest radiograph is a rare finding although ossification of an atrial myxoma has been reported. ${ }^{3-5} \mathrm{~A}$ calcified ball thrombus can present a similar appearance macroscopically, but the mass in this patient arose by a pedicle from the limbus of the fossa ovalis and was easily distinguishable histologically as a tumour. Calcification within a myxoma may follow tumour necrosis secondary to central infarction and repeated trauma and compression of the tumour. Once started, calcification may well encourage further necrosis by interfering with the blood supply of the myxoma and thereby cause the formation of a cardiac "stone".

It is well established that left atrial myxomas may mimic mitral valve lesions, particularly stenosis, but significant valvular pathology is usually absent. Mitral regurgitation caused by chordal rupture has been reported in association with left atrial myxomas and is though to be secondary to a direct "wrecking ball" action of the prolapsing tumour on the mitral valve apparatus. ${ }^{6}$ 7 We consider that the atrial myxoma in this patient did not interfere with mitral valve function and that it was an incidental finding.

\section{References}

${ }^{1}$ Selzer A, Kelly JJ, Vannitamby N, Walker P, Gerbode F, Ferth WJ. The syndrome of mitral insufficiency due to isolated rupture of the chordae tendinae. Am J Med 1967; 43:822-36.

${ }^{2}$ Singh R, Schrank JP, Nolan SP, McGuire LB. Spontaneous rupture of mitral chordae tendinae. JAMA 1972; 219:189-93.

${ }^{3}$ Oliver GC, Missen GAK. A heavily calcified right atrial myxoma. Guy's Hosp Rep 1966;115:37-63.

${ }^{4}$ Sharratt GP, Grover ML, Monro JL. Calcified left atrial myxoma with floppy mitral valve. Br Heart J 1979;42: 608-10.

${ }^{5}$ Fleming HA, Stovin PGI. Calcified right atrial massreport of a case and discussion of the differential diagnosis. Thorax 1972;27:373-81.

${ }^{6}$ Goodwin JF, Stanfield CA, Steiner RE. Clinical features of left atrial myxomas. Thorax 1962;17:91-110.

${ }^{7}$ Harvey WP. Clinical aspects of cardiac tumours. Am J Cardiol 1968;21:328-43. 